\title{
ETNOMATEMÁTICA: uma aproximação com o trabalho como princípio educativo
}

\author{
Claudio Fernandes da Costa30
}

\section{RESUMO}

Este texto tem como objetivo aprofundar estudos sobre a centralidade do trabalho, como princípio educativo, a partir da perspectiva ontológica, materialista e dialética, em Marx, e relacioná-lo/aproximá-lo com a Etnomatemática como concebida por Ubiratan D Ambrosio. Neste sentido, buscamos identificar aspectos ontológicos na/da formulação Ełnomatemática d’ambrosiana que contribuem para a referida aproximação, bem como vislumbrar o seu potencial políticopedagógico. Por outro lado, examinamos o fato de que, embora não seja descartado, o princípio educativo do trabalho não é central na prática e na pesquisa em Etnomatemática, inspirada no Programa lakatosiano. Para atingir tais objetivos, além dos dois autores principais, nos apoiamos, ainda, em Barata-Moura (2008), Duayer $(2010,2015)$, Ferreira (2007), Frigotto (2005, 2015), e Miarka (2011). Os resultados e conclusões parciais deste trabalho teórico apontam, por um lado, a sintonia e relevância teórico-pedagógica da referida aproximação, para pesquisas e práticas que tomam como base a ontologia da Etnomatemática d'ambrosiana. Por outro lado, indicam uma "diferença substantiva" entre a "dinâmica" e o relativismo do Programa de Pesquisa lakatosiano e o Programa Etnomatemática d’ambrosiano, razão pela qual entendemos que a prática e a pesquisa em Ełnomatemática, embora admitam o trabalho, não identificam nem se relacionam com a relevância ontológica desta categoria.

Palavras-chave: Programa Etnomatemática. Trabalho como Princípio Educativo. Ontologia.

\section{ETHNOMATHEMATICS: an approach to work as an educational principle}

\begin{abstract}
This text aims at deepening studies on the centrality of work, as an educational principle, from the ontological, materialist and dialectical perspective, in Marx, and to relate it to the ethno-mathematics as conceived by Ubiratan D'Ambrosio. From this point of view, we seek to identify ontological aspects in the ethnomathematical formulation of d'ambrosio, which contributes to this approximation, as well as to

30 Doutorado em Educação pela Pontifícia Universidade Católica do Rio de Janeiro. Docente do Instituto de Educação de Angra dos Reis - IEAR, da Universidade Federal Fluminense. E-mail: claudiofernandesdacosta@gmail.com.
\end{abstract}


glimpse its political-pedagogical potential. On the other hand, we examine the fact that, although not discarded, the educational principle of work is not central to practice and research in ethno-mathematics, inspired by the lakatosian program. In order to reach these goals, in addition to the two main authors we are based on, we also rely on the support of Barata-Moura (2008), Duayer (2010, 2015), Ferreira (2007), Frigotto (2005, 2015), and Miarka (2011). The results and partial conclusions of this theoretical work points at, on one hand, to the tune and theoretical pedagogical relevance of this approach, for researches and practices that take as basis on the d'ambrosian ontology of Ethno-mathematics and, on the other hand, they indicate a "substantive difference" between the "dynamics" and relativism of the lakatosian Research Program and the Ethno-mathematic Brahmanian Program, the reason why we understand that the practice and research in Ethnomathematics, while admitting work, does not Identify or relate to the ontological relevance of this category.

Keywords: Ethnomathematics Program. Work as Educational Principle. Ontology.

\section{ETNOMATEMÁTICA: una aproximación al trabajo como principio educativo}

\section{RESUMEN}

Este texto tiene como objetivo profundizar los estudios sobre la centralidad del trabajo como principio educativo, desde el punto de vista ontológico, materialista y dialéctico en Marx, y relacionarlo / aproximarlo con la Etnomatemáticas como fue concebida por Ubiratan D 'Ambrosio. En este sentido, buscamos identificar aspectos ontológicos en la formulación etnomatemática d’ambrosiana, contribuyendo a dicho planteamiento, y visualizando su potencial político-pedagógico. Por otro lado, se analiza el hecho de que, aunque no se descarta, el principio educativo del trabajo no es central en la práctica y en la investigación en Etnomatemática inspirado en el Programa lakatosiano. Para lograr estos objetivos, además de los dos autores principales, nos apoyamos asimismo en Barata-Moura (2008), Duayer (2010, 2015), Ferreira (2007), Frigotto $(2005,2015)$, y Miarka (2011). Los resultados parciales y conclusiones de este trabajo teórico indican, por un lado, la sintonía y relevancia teórico-pedagógica de este enfoque en la investigación y la práctica que se basan en la ontología de la Etnomatemáticas d'ambrosiana. Por otro lado, indican una "diferencia sustancial" entre la "dinámica" y el relativismo del Programa de Investigación lakatosiano y el Programa de Etnomatemáticas d`ambrosiano, razón por la cual entendemos que la práctica y la investigación en Etnomatemática, aunque admiten el "trabajo", no se identifican ni se relacionan con la relevancia ontológica de esta categoría.

Palabras clave: Programa Ełnomatemáticas. Trabajo como Principio Educativo. Ontología. 


\section{INTRODUÇÃO}

Este trabalho decorre de pesquisa em andamento que visa aprofundar reflexão sobre a centralidade do trabalho como princípio educativo, a partir da perspectiva ontológica, materialista e dialética, em Marx, e relacionálo/aproximá-lo com a Etnomatemática e/ou com o Programa Etnomatemática, como concebidos por Ubiratan D`Ambrosio sob a influência da "dinâmica" dos Programas de Pesquisa Científica (PPC's) de Irme Lakatos (1989).

De acordo com o escopo da presente proposta, concordamos com Barata-Moura (2008), referindo-se a Marx, de que é decisivo considerarmos os contornos de uma ontologia para a "clarificação do horizonte material sobre que se levanta toda a problemática do pensamento e da prática transformadora". Assim, destaca-se "a própria "vida do material" que importa surpreender e tornar inteligível no seu "movimento efetivamente real" (BARATA-MOURA, 2008, p.4) (grifos nossos).

Neste sentido, buscamos, por um lado, identificar aspectos ontológicos na/da formulação Etnomatemática d’ambrosiana que confluem para a referida aproximação, bem como vislumbrar o seu potencial políticopedagógico. Por outro lado, examinamos o fato de que, embora não seja descartado, o princípio educativo do trabalho, não é inteligível, ontologicamente, na prática e na pesquisa relativas ao Programa Etnomatemática de inspiração lakatosiana. Neste último caso, trabalhamos com a hipótese da existência de uma diferença substantiva neste processo.

Assim, decidimos aprofundar a categoria trabalho enquanto inteligibilidade concreta, e atuação prática, esclarecida e determinada, buscando possíveis relações, próximas e/ou contraditórias com o que designamos por princípios/aspectos fundantes e/ou "núcleo firme" da Etnomatemática.

Destacamos que se trata de laborar sobre duas perspectivas em atual e permanente investigação, já que "como é sabido, Marx não compôs 
qualquer tratado de Ontologia" (Barata-Moura, 2008, p.2), tanto quanto D’Ambrosio não desenvolveu, pelo menos explicitamente, uma reflexão sobre "núcleo firme" (que consideramos a perspectiva ontológica dos Programas de Lakatos) em seus trabalhos.

Por razões teórico-metodológicas que adensamos ao longo do texto, privilegiamos a ontologia, como o terreno sobre o qual buscaremos enfatizar e aproximar aspectos que confluem na caracterização onto-histórica e criativa do trabalho em Marx, bem como na perspectiva que constitui a Etnomatemática em D`Ambrosio. Para encaminharmos este desafio, além dos dois autores principais, nos apoiamos, sobretudo, em Barata-Moura (2008), Duayer (2010, 2014), Ferreira (2007), e Miarka (2011).

Neste sentido, nos será muito útil, metodologicamente, considerarmos a perspectiva ontológica dialética, de Marx, quando comparada à de Hegel: "é de dentro da materialidade do ser (não mais de antemão resolvida em "pensado") que, como figura de sua mediação, se ergue, e tem que ser compreendida na sua função e especificidade toda a atividade - desde logo a do pensar" (BARATA-MOURA, 2008, p.5) (grifos nossos).

Ou seja, Marx inverte (não desprezando) a perspectiva de Hegel para quem o processo de pensamento (idéia) é autônomo, o demiurgo do efetivamente real, representando, este real, apenas o fenômeno exterior do pensamento.

Para o método dialético de Marx: "inversamente, o "ideial" não é senão o material transposto e traduzido na cabeça dos homens." (Idem). Por outro lado, "a dialética não se configura apenas como uma adjunção subjetiva (humana) à materialidade do ser (que dela se encontraria desprovida)". A dialética "faz um com a própria materialidade do ser, na medida em que, a este, a historicidade não é acidental, mas constitutiva" (p.7) (grifos nossos).

Identificadas, em linhas gerais, as referências ontológicas centrais, sobretudo em Marx, através das quais pretendemos estabelecer a referida aproximação com aspectos fundantes da Etnomatemática d`ambrosiamna, 
bem como investigar aspectos contraditórios do Programa lakatosiano, seguimos inicialmente buscando, refletindo e cotejando elementos que, a nosso ver, constituem uma ontologia na base da formulação D'ambrosiana.

\section{PRINCÍPIOS ONTOLÓGICOS DA ETNOMATEMÁTICA D`AMBROSIANA}

Segundo Ferreira (2007), D'Ambrosio nos seus escritos, revela o que pensa deva constituir o "núcleo do Programa", isto é, "geração, organização e difusão do conhecimento e afirma que, ao difundir o conhecimento, temos a Educação" (FERREIRA, 2007, p.274).

O próprio D`Ambrosio (1999), ampliando esta formulação, revela outros importantes elementos da "vida do material" que constituem o ser e o seu movimento. "O Programa Etnomatemática não se esgota no entender o conhecimento [saber e fazer] matemático das culturas periféricas. Procura entender o ciclo da geração, organização intelectual, organização social e difusão desse conhecimento". Acrescenta que "no encontro de culturas há uma importante dinâmica de adaptação e reformulação acompanhando todo esse ciclo, inclusive a dinâmica cultural de encontros [de indivíduos e de grupos]". Por fim, conclui: "O Programa Etnomatemática tem como referências categorias próprias de cada cultura, reconhecendo que é própria da espécie humana a satisfação de pulsões de sobrevivência e transcendência absolutamente integradas, como numa relação simbiótica" (D'AMBROSIO, 2009, p.4) (grifo nosso).

Esta descrição mais detalhada envolvendo as referências do Programa de Pesquisa Etnomatemática sempre nos instigou a pensar o "encontro" das "categorias próprias de cada cultura", com as categorias próprias da "espécie humana" relacionadas à "sobrevivência e transcendência". Nesta perspectiva é que nos propomos a pensar a relação de proximidade e/ou complementaridade (o que não exclui diferenças e divergências) entre categorias predominantes na Etnomatemática de cada 
cultura, "reconhecendo" a categoria trabalho como fundante da própria existência do ser e da espécie humana.

Prosseguimos, então, buscando ampliar e compreender os elementos centrais desta formulação, através de outra conhecida citação do próprio D'Ambrosio (2009) que, embora sintética, é bastante elucidativa acerca da concepção de mundo e de ser (indivíduo e sociedade), ou da ontologia que sustenta o Programa Etnomatemática.

\begin{abstract}
Indivíduos e povos têm, ao longo de suas existências e ao longo da história, criado e desenvolvido instrumentos de reflexão, de observação, instrumentos materiais e intelectuais [que chamo ticas] para explicar, entender, conhecer, aprender para saber fazer [que chamo matema] como resposta a necessidades de sobrevivência e de transcendência em diferentes ambientes naturais, sociais e culturais [que chamo etnos]. Daí chamar o exposto acima de Programa Etnomatemática (p.60) (grifos nossos) (D'AMBROSIO, 2009, p.60).
\end{abstract}

Seguindo em busca da "essência" desta formulação, convém lembrar que para D`Ambrósio (2010), o ponto de partida é entender o fenômeno vida, como algo inconcluso e complexo, em permanente transformação e sujeito a uma dinâmica que não conhecemos. Neste fenômeno carregado de incertezas e contradições intrínsecas, explica que se podem identificar "três elementos fundamentais" e mutuamente essenciais para que a vida se realize, ao que ele denomina de Triângulo da Vida: INDIVíDuo;

\title{
OUTRO(s)/SOCIEDADE; NATUREZA.
}

Nesta perspectiva, o homem é um organismo vivo, complexo na sua definição e no seu funcionamento, sujeito aos mesmos comportamentos básicos de todo ser vivo. Neste sentido, busca sobrevivência. Entretanto, diferentemente dos demais seres vivos, busca algo além da sobrevivência. Esta diferença se manifesta nas seguintes inter(mediações) criadas pelo homem para a resolução do triângulo da vida:

INDIVÍDUO instrumentos/tecnologia NATUREZA

INDIVÍDUO comunicação/emoções OUTRO(s)/SOCIEDADE

OUTRO(s)/SOCIEDADE produção/trabalho NATUREZA 
Segundo D'Ambrosio, entrevistado por Miarka (2011), este é o ponto de partida consistente de sua concepção de mundo e de ser (resiste a testes teóricos, a vários enfoques culturais, faz sentido, funciona) que fundamenta a sua elaboração sobre a Etnomatemática.

\begin{abstract}
...indivíduo, o outro e natureza ou realidade e natureza. Pra mim, esse é o ponto de partida. Já nesse ponto de partida, eu encontro a questão do etno. [...] Aí que entra o etno, que é basicamente respeito pelas outras visões. Bem, as outras explicam a vida de uma outra forma. Eu aí sigo aquilo que eu tô achando mais adequado pro tipo de vida que a gente tem pra cá e aceito essa coisa [...]. Esse triângulo resiste a esses, vamos dizer, testes, testes teóricos para dizer se esse triângulo faz sentido. Faz. Bom, aí chega o outro, um diferencial. Aparece uma espécie que se diferencia das outras. Essa espécie que se diferencia das outras, do mesmo modo como você vai explicar? Então o triângulo passa a ser um triângulo com... modificado, entre os lados. Isso você encontra em meus livros todos. Entre os lados você tem as intermediações. Este é o fenômeno da vida humana. Aquele triângulo de sobrevivência mais esse triângulo que é resultado da vontade. Bom, esse é o ponto de partida. [...] $E$ isso aí resiste a vários enfoques culturais, essa minha explicação funciona. Eu tenho, pode ser que eu pareça um diferente, mas tudo que eu tenho visto funciona. Então eu considero este um ponto de partida. [...] Seria esse valor universal... (MIARKA, 2011, p. 55-57).
\end{abstract}

Ainda segundo D'Ambrosio, os "acertos e equívocos" na produção dessas intermediações resultam do encontro do COMPORTAMENTO e do CONHECIMENTO, que denomina de CONSCIÊNCIA.

D`Ambrosio (2010) caracteriza o comportamento humano como resultado de duas grandes "pulsões". A sobrevivência do indivíduo e da espécie que se situa na dimensão do momento. A transcendência do momento, que se situa numa outra dimensão, levando o homem a indagar por quê?, como?, onde?, quando?

D'Ambrosio (2009) situa, ainda, o comportamento, que também chama de prática, fazer, ou ação, no presente, quando se manifesta a [inter]relação do indivíduo com o seu meio ambiente, natural e sociocultutal.

Além disso, afirma ele: "vejo sobrevivência e transcendência como a essência de ser[verbo]humano" (D`AMBROSIO, 2009, p.50). Podemos então, concluir que o comportamento, traduzido pela ação prática de 
fazer/produzir a vida, é a materialidade pela qual se realiza esta essência do Ser humano. Voltaremos, mais adiante a este pressuposto fundamental, evidenciando uma determinada atividade, central no comportamento humano.

Como resposta à sobrevivência, o homem define suas relações com a natureza e com o outro e desenvolve as intermediações já mencionadas. Na resposta à pulsão de transcendência o "homem" transita no passado e no futuro, desenvolvendo mitos e artes, religiões e ciências. No encontro com o outro, também em busca de sobrevivência e de transcendência, desenvolve-se a COMUNICAÇÃO.

A partir destes pressupostos, D'Ambrosio (1996) expressa, ainda, o que denomina de ciclo vital.

[...] $\rightarrow$ REALIDADE informa INDIVÍDUO que processa e executa uma AÇÃO que modifica a REALIDADE que informa INDIVÍDUO $\rightarrow[\ldots]$ (D'AMBROSIO, 1996, p.20).

Neste ciclo, ressalta que "o processamento dessa informação tem como resultado estratégias para a ação" (p.21) (grifos do autor). Assim, concebe "o comportamento como elo entre a realidade, que informa, e a ação, que modifica a realidade." E conclui que "a ação gera conhecimento, gera a capacidade de explicar, de lidar, de manejar, de entender a realidade, gera o matema" (D'AMBROSIO, 1996, p.22-23).

Em outras palavras, D'Ambrosio (1986) acrescenta que:

Essa modificação da realidade pela ação do indivíduo provoca imediatamente nova reflexão, novo comportamento, nova interação com informação já memorizada e informação recémadquirida (...), e nova ação, com imediato efeito sobre a realidade (...). É o indivíduo como feitor da realidade (...), é o indivíduo elevado a criador (D'AMBROSIO, 1986, p.49).

Ainda neste sentido, D'Ambrosio (2009) salienta que a ação do homem é impulsionada pela consciência em direção à sobrevivência e à transcendência, "ao saber fazendo e fazer sabendo". Afirma que "o processo de aquisição do conhecimento é, portanto, essa relação dialética 
saber/fazer, impulsionada pela consciência (...)" (D'AMBROSIO, 2009, p.5354).

Neste sentido, Marafon (2000) destaca que D'Ambrósio "se baseia na relação dialética sobrevivência/transcendência". Em decorrência disso, afirma a autora que "o homem atua sobre a natureza externa e a modifica, modificando, ao mesmo tempo, sua própria natureza" (MARAFON, 2000, p.2).

Acreditamos ter trazido, até aqui, concepções de mundo e de conhecimento suficientes para caracterizar ontologicamente a Etnometemática d'ambrosiana, em proximidade com a ontologia materialista e dialética de Marx. Entretanto, sentimos falta de um elemento concreto na dinâmica das referidas mediações ou [inter]relações entre indivíduo e natureza, ou indivíduo e realidade, que materialize explicitamente $\mathrm{O}$ encontro de comportamento (ação, prática) e conhecimento, como consciência, e dê sustentação e amálgama ao processo (ciclo) de produção da vida e de humanização desse indivíduo.

\section{O TRABALHO E A ETNOMATEMÁTICA D`AMBROSIANA}

Entendemos que Frigotto (2015), nos oferece "inteligibilidade concreta" a esta lacuna, evidenciando o trabalho e sua perspectiva ontológica como a atividade vital através da qual o ser humano se diferencia da fixação dos demais seres vivos, determinados pelo instinto de sua espécie. "Esta superação dá-se por meio da consciência que the permite projetar e antecipar sua ação e modificar a natureza, da qual se origina, e criar o mundo propriamente humano" (FRIGOTTO, 2015, p.10, grifos nossos).

Neste sentido, explica que em sua dimensão imperativa, o trabalho aparece como "atividade que responde à produção dos elementos necessários à vida biológica dos seres humanos. Concomitantemente, porém, constitui-se no fundamento para responder às necessidades de sua 
vida cultural, social, estética, simbólica, lúdica e afetiva". E conclui, acrescentando, que por serem históricas, tais necessidades assumem especificidades no tempo e no espaço. Que o tempo de trabalho a ser dedicado em resposta a estas necessidades "varia de acordo com os avanços dos instrumentos e técnicas de produção, e a quem beneficiam estes avanços científicos e técnicos vai depender da natureza das relações sociais dominantes" (FRIGOTTO, 2015, p.11, grifo nosso).

Neste conjunto de fundamentos vinculados à necessidade imperativa, imediata e historicamente determinada de sobrevivência, que, transcendendo o momento imediato, numa relação "simbiótica", "concomitante", e porque não dizer dialética, atinge o desenvolvimento dos mitos, artes, religiões e ciência, ou do cultural, social, estético, simbólico, lúdico e afetivo, consideramos que residem elementos suficientes para relacionar os significados atribuídos por D`Ambrosio (2009, 2010) para comportamento (prática, fazer, ou ação), conhecimento, e consciência, com o trabalho no sentido de atividade humana consciente, criativa e educativa, fundante do ser individual e social.

Assim, sendo, a importância do "trabalho" explicitado em D Ambrosio (2010) como inter(mediação), entre "sociedade e natureza", produtiva e essencial para a sobrevivência da própria espécie, certamente estende-se como atividade (ação) central na relação "indivíduo-natureza", a requerer a produção de instrumentos/tecnologia como meios de produção e compreensão da vida, o que implica, por sua vez, a imprescindível necessidade de socializar tais artefatos, movimento que, no encontro com o(s) outro(s), promove e desenvolve o fenômeno da "comunicação" e das "emoções humanas", elementos fundamentais no processo que caracterizamos como "educativo".

Dito de outra maneira, ao vislumbrarmos, na perspectiva D'ambrosiana, a essência do trabalho na produção imediata e mediata da vida humana, evidenciamos também o seu principio educativo, na medida em que, como atividade (ação) vital, requer e implica a criação e 
desenvolvimento de instrumentos materiais e intelectuais, de reflexão e de observação (Ticas), para explicar, entender, conhecer, aprender para saber fazer (Matema), como resposta a necessidades de sobrevivência e de transcendência em diferentes ambientes naturais, sociais e culturais (Etnos).

Na medida, ainda, em que este processo desenvolvido por indivíduos e povos ao longo de suas existências, e ao longo da história, destaca a fundamental importância atribuída por D`Ambrosio (2010) à historicidade como constitutiva do ser individual, e do ser social, trabalhamos com a idéia de que o trabalho como princípio educativo, em Marx, vincula-se essencialmente ao núcleo da própria Ełnomatemática.

Mas, se apontamos fundamentos e aspectos centrais da Etnomatemática, cuja inteligibilidade buscamos na confluência com categorias envolvidas na concepção ontológica de trabalho em Marx, cabe-nos melhor explicitar esta formulação.

(...) O trabalho é um processo entre o homem e a natureza, um processo em que o homem, por sua própria ação, medeia, regula e controla seu metabolismo com a natureza. (...) Ele põe em movimento as forças naturais pertencentes à sua corporeidade, braços, pernas, cabeça e mãos, a fim de se apropriar da matéria natural numa forma útil à própria vida. Ao atuar, por meio desse movimento, sobre a natureza externa a ele e, ao modificá-la, ele modifica, ao mesmo tempo, sua própria natureza (MARX, 1983, p. 149).

Com base nesta concepção, Frigotto (2015) ressalta que no próprio processo histórico de tornar-se humano, surge a atividade que denominamos de trabalho em seu sentido ontocriativo, como algo específico do homem (p.10).

Ainda com base em Marx, Frigotto (2005) esclarece que:

O trabalho como princípio educativo vincula-se, então, à própria forma de ser dos seres humanos. Somos parte da natureza e dependemos dela para reproduzir a nossa vida. E é pela ação vital do trabalho que os seres humanos transformam a natureza em meios de vida. Se essa é uma condição imperativa, socializar o princípio do trabalho como produtor de valores de uso, para manter e reproduzir a vida, é crucial e "educativo". (...) É dentro desta perspectiva que Marx sinaliza a dimensão educativa do trabalho, mesmo quando o

Revista Exitus, Santarém/PA, Vol. 7, №2, p. 150-172, Maio/Ago 2017. 
trabalho se dá sob a negatividade das relações de classe existentes no capitalismo. A própria forma de trabalho capitalista não é natural, mas produzida pelos seres humanos. A luta histórica é para superá-la (FRIGOTTO, 2005, p.1-2).

Na mesma direção, Barata-Moura (2015) reafirma o potencial educativo e transgressor do trabalho, já que pela radicalidade de sua estrutura, tece-se e entretece-se uma negatividade formadora.

\begin{abstract}
O trabalho, pela sua natureza constitutiva, é um processo de transformação. Pro-duz, porque faz advir (...) formas (não necessariamente reificadas na função de «mercadoria») que alteram (fazem assumir uma figura outra) um dado estado prévio de elementos disponíveis (...). Acolhido, tomado, e visto, nesta radicalidade de estrutura, o trabalho - tal como a prática, ou como qualquer processo criativo - tece-se e entretece-se de «negatividade» formadora. Opera como trans-gressão de uma positividade existencialmente dada, e como engendramento de configurações anteriormente não advindas. À luz do sentido que esta atitude ex-põe: a educação é um trabalho do ser na sua figura humana (BARATA-MOURA, 2015, p.15).
\end{abstract}

Observemos que Frigotto (2005) refere-se à atualidade do princípio educativo do trabalho, cuja dimensão ontológica se presta a iluminá-lo como possibilidade histórica de transformação, mas não sem explicitar que esta é uma questão complexa e de difícil compreensão, considerando aqueles que vivem da venda da sua força de trabalho, ou dos milhões de desempregados, subempregados e com trabalho precário. "Como pode ser educativo algo que é explorado e, na maior parte das vezes, se dá em condições de não escolha? Como extrair positividade de um trabalho repetitivo, vigiado e mal remunerado?" (FRIGOTTO. 2005, p.1).

Entretanto, em acordo com D'Ambrosio sobre a essência da prática para o "ser" humano, Frigotto (2005) destaca que o trabalho, em Marx, pressupõe esta prática como ponto de partida do conhecimento, reafirmando o seu papel educativo e transformador.

Na relação dos seres humanos para produzirem os meios de vida pelo trabalho, não significa apenas que, ao transformar a natureza, transformamos a nós mesmos, mas também que a atividade prática é o ponto de partida do conhecimento, da cultura e da 
conscientização. A direção que assume a relação trabalho e educação nos processos formativos não é inocente. Traz a marca dos embates que se efetivam no âmbito do conjunto das relações sociais. (...) é parte da luta hegemônica entre capital e trabalho (FRIGOTTO, 2005, p.1-2).

Ainda neste sentido, D'Ambrosio, em entrevista a Miarka (2011), explica a essência da prática como materialidade do conhecimento, da consciência e da educação.

[...] Quer dizer, o ad hoc você faz aquela coisa. Esse é o primeiro passo. [...] No momento que você realizou aquilo, você conseguiu fazer, você adquire um conhecimento, que é o saber sobre aquele fazer. Bom, uma vez tendo o conhecimento do saber sobre aquele fazer, você tem o método, pois da próxima vez você não faz tentativas e erros. Você usa o seu saber para fazer. Isto é que mostra como saber e fazer estão juntos, mas tomar consciência disso é você ter domínio sobre si. E isso eu acho um grande objetivo da educação em um sentido amplo (MIARKA, 2011, p.79-80).

A título de síntese, mas sem a pretensão de esgotar o tema, recorremos novamente a Barata-Moura (2008), citando Marx: "todo o viver social é essencialmente prático". Segundo o autor, esta síntese se justifica porque "na sua realidade efetiva a essência do homem (...) é o conjunto das relações sociais em curso histórico de reconfiguração prática.". (p.16). Por fim, adverte que "é decisivo não desmerecer nem menosprezar a feitura humana (prática) da história como uma dimensão real da própria contraditoriedade material de que o ser se tece e entretece" (BARATAMOURA, 2008, p.18).

\section{PROGRAMA ETNOMATEMÁTICA: aproximações e diferenças com Lakatos}

Se, por um lado, constatamos uma proximidade bastante consistente entre as ontologias que sustentam o trabalho (como princípio educativo) e a Etnomatemática d’ambrosiana, nos dois sistemas de pensamento em questão, por outro, esta aproximação não implica a centralidade da categoria trabalho em pesquisas e práticas relativas ao Programa Etnomatemática lakatosiano. Esta compreensão nos leva a admitir, em 
relação a este programa, uma diferença substantiva que buscamos elucidar com a ajuda de Duayer $(2010,2012,2015)$.

Segundo Duayer (2015), as diferenças de posição quando substantivas, se resolvem em diferenças ontológicas.

Dito de outra maneira, "(...) controvérsias substantivas entre sistemas teóricos distintos não admitem resolução empírica, e precisamente porque o terreno empírico em relação ao qual são plausíveis é traçado por suas ontologias particulares". Além do que podemos imaginar "(...) a interseção de diferentes "sistemas teóricos" constituindo um domínio empírico em comum, em relação ao qual, portanto, são empiricamente equivalentes" (DUAYER, 2012, p.40).

Neste sentido, na medida em que o cotejamento ontológico entre Trabalho e Etnomatemática indicou uma sintonia que, entretanto, explicitou uma "controvérsia" que não pode ser identificada no domínio empírico, concluímos que, para além das duas jurisdições ontológicas e teóricas em questão, existe pelo menos mais uma, definida por outro campo teórico e/ou ontológico responsável pela referida diferença.

Assim sendo, consideramos a perspectiva lakatosiana presente no Programa Etnomatemática d’ambrosiano, como este outro campo ontológico e teórico que compõe o domínio empírico considerado, a ser necessariamente analisado para elucidarmos a controvérsia em questão.

Na medida em que D'Ambrosio caracteriza a Etnomatemática como teoria do conhecimento e como um Programa de Pesquisa lakatosiano, buscaremos enfrentar esta questão, apoiados no encaminhamento de resolução ontológica de Duayer (2015), proposto através de uma análise no âmbito da filosofia da ciência (2010), o que nos permite problematizar os PPC's formulados por Irme Lakatos um de seus mais importantes representantes.

As idéias de Mario Duayer vêm ao encontro das questões e referências centrais deste trabalho, sobretudo porque ao invés de tratar "diretamente" das determinações sociais das formas de pensamento, das formações ideais, 
procura mostrar como essas "noções, em geral qualificadas como relativistas, irrealistas, ou idealistas", encontram suporte e estímulo em certas concepções na filosofia da ciência ${ }^{31}$, e na prerrogativa do pensamento científico junto à sociedade moderna (DUAYER, 2010, p.60).

Neste sentido, O próprio Lakatos (1989) define os PPC's como programas de investigação constituídos por um núcleo firme persistente, uma heurística negativa que especifica o núcleo firme, convencionalmente aceito (e, portanto, irrefutável por decisão metodológica de seus defensores), e uma heurística positiva, uma poderosa maquinaria que, com a ajuda de técnicas matemáticas sofisticadas para predizer e resolver problemas, busca assimilar anomalias, convertendo-as, quando possível, em evidência positiva do programa. De acordo com uma idéia unificadora, esta heurística esboça a construção de um grande cinturão protetor de hipóteses auxiliares observacionais, para proteger o núcleo firme de refutações. Prevendo anomalias devido à pressão empírica, o cinturão é desenhado para ser refutável, ou seja, modificado constantemente no intuito de que as refutações atinjam no máximo algumas de suas hipóteses, deixando intacto o núcleo firme do programa.

Duayer (2010) nos ajuda a ampliar a versão lakatosiana de ciência, destacando a sua metodologia.

Na versão lakatosiana, a ciência deve ser compreendida como consistindo de sistemas ou famílias de teorias, em lugar de teorias isoladas. A ciência, sob essa ótica, funciona como um sistema de teorias em permanente processo de aperfeiçoamento e transformação. Tais sistemas ou tradições teóricas, em cada ciência particular, constituem um programa de pesquisa cientifica (PPC), de modo que é possível haver em uma dada ciência uma variedade de tradições teóricas, cada qual evolvendo de acordo com os protocolos de seu PPC. Em linhas gerais, na explanação lakatosiana os PPCs são constituídos por dois tipos de regras metodológicas, uma heurística negativa e uma positiva. A heurística negativa de um PPC estabelece as investigações impróprias em seu interior;

31 Para Duayer (2010), a ênfase na filosofia da ciência não significa que o relativismo esteja circunscrito e/ou deva ser criticado, se for o caso, apenas neste âmbito, já que constitui a atmosfera espiritual contemporânea, presente, também, na cultura, na ética, na política, na arte, no pensamento cotidiano, etc. 
especificamente, desautorizam a investigação do núcleo duro do PPC - ou seja, o conjunto de axiomas que compõem a sua parte irrefutável. A heurística positiva define as linhas de pesquisa legítimas, abonadas pelo PPC, representando o conjunto de indicações para aperfeiçoar e modificar as teorias que orbitam o núcleo rígido, compondo o cinturão protetor do PPC, sua parte refutável (p.70).

Na perspectiva deste autor, a teoria de Lakatos nos oferece o seguinte cenário sobre o desenvolvimento da ciência:

(...) em cada ciência, no curso de sua evolução, há vários PPCs concorrentes, cada um com seu núcleo rígido, do qual se irradiam teorias cada vez mais complexas e abrangentes. Como os núcleos rígidos são irrefutáveis, segue-se que cada PPC está fundado em uma ontologia que the é específica, uma descrição do mundo própria que o diferencia dos demais. Dada a imutabilidade do núcleo rígido, a dinâmica dos PPCs recai sobre as teorias continuamente criadas, aperfeiçoadas e transformadas que orbitam o núcleo rígido. De maneira similar à teoria de Kuhn, a sobrevivência de um PPC depende exclusivamente de sua dinâmica expansionista, que, também aqui, se resolve na capacidade de suas teorias colonizarem um território empírico cada vez mais extenso (DUAYER, 2010, p.70).

Após examinarmos, naquilo que interessa ao nosso trabalho, os aspectos centrais da tradição positivista, em especial do positivismo lógico, bem como as críticas, a este, por dois dos principais pensadores póspositivistas, a saber, Thomas Kuhn e Imre Lakatos, concluímos, com a ajuda de Duayer (2010), que tais teorias (as críticas e as criticadas) não diferem substantivamente, na medida em que para elas "A ciência funciona tal como preconizado pelo modelo H-D [Hipotético-Dedutivo] e, em consequência, suas teorias são construídas tendo em vista exclusivamente sua capacidade preditiva" (DUAYER, 2010, p.71).

Segundo o próprio Lakatos (1989), "Uma série de teorias é teoricamente progressiva [...] se cada nova teoria tem algum acréscimo de conteúdo empírico em relação à teoria que a antecedeu; isto é, se predisse algum fato novo [...]" (LAKATOS, 1989, p.38).

Destaca-se, entretanto, que diferente da tradição positivista, as concepções de Kuhn e Lakatos refutam explicitamente a sua perspectiva 
anti-metafísica, já que paradigma e núcleo rígido, respectivamente, codinomes para a ontologia, "São o reconhecimento explícito de que toda ciência é uma interpretação do mundo - uma ontologia - antes de ser uma caixa de apetrechos cognitivos para manipulá-lo. É significação do mundo antes de ser um instrumento para lidarmos com ele" (DUAYER, 2010, p.71-72).

Por outro lado, Duayer (2010) destaca e analisa a interdição e/ou irrelevância atribuída a esta mesma ontologia no pensamento contemporâneo, que vigora há séculos no pensamento ocidental. Em outras palavras, para Lakatos, "assim como Kuhn, a ontologia, sob a figura de núcleo rígido irrefutável, é admitida como elemento constitutivo da ciência, mas é igualmente irrelevante, pois os PPCs não se medem por suas ontologias, incomensuráveis, mas pela eficácia preditiva de suas teorias" (p.71).

A titulo de síntese, Duayer (2010) afirma que na tradição positivista a interdição é positiva, já que "não há ontologia ou problemas ontológicos que mereçam ser levados em conta", enquanto nas correntes póspositivistas contemporâneas, a interdição é negativa, ou seja, "a vida social sempre está apoiada em ontologias, todas relativas às formas de vida correspondentes e, portanto, inescrutáveis" (p.72).

Duayer (2010) enfatiza, assim, o absurdo de tal concepção na medida em que todas as nossas crenças científicas, morais, sociais, estéticas etc. "são relativas à forma de vida em que estão a cada vez encerradas. E que crenças ou valores de formas de vida diferentes são incomunicáveis, são igualmente verdadeiros em relação à respectiva forma de vida". Ou seja, "mundos diferentes são mundos incomunicáveis". Em outras palavras, "não é possível oferecer argumentos cognitivos a favor ou contra qualquer crença sobre o mundo. A crítica é impossível, pois todas as crenças são igualmente válidas relativamente às práticas e relações das quais são crenças" (DUAYER, 2010, p.72).

Por fim, Duayer (2010) conclui que "essa é a atmosfera espiritual de nossa época" na medida em que "argumentos filosóficos sofisticados (...) nos 
proíbem de pensar no mundo para além do perímetro de sua configuração atual". Sinteticamente pode-se dizer que "tudo é relativo. Só há um absoluto, o mundo regido pelo capital [...] (P.72).

Julgamos que este conjunto de argumentações é suficiente para analisar a questão que enunciamos anteriormente, buscando elucidar a diferença substantiva, ou ontológica, entre a categoria trabalho e a Etnomatemática, sobretudo inspirada no Programa lakatosiano.

Buscaremos, portanto, indicar, como e porque a aproximação ontológica verificada entre o trabalho como princípio educativo e a Etnomatemática d'ambrosiana, não implica uma aproximação com a perspectiva ontológica lakatosiana.

Neste sentido, defendemos a idéia de que embora D'Ambrosio se inspire na perspectiva lakatosiana, não adere a ela completamente. Apropria-se, mais especificamente, da sua "dinâmica", vinculada, entretanto, ao relativismo ontológico dos PPC's, expresso, em nossa análise, pela admissão da(s) ontologia(s), mas, sobretudo, pelas suas interdições. Esta apropriação, mesmo que indireta, dificultaria, assim, a clara inteligibilidade ontológica e, portanto, a possibilidade objetiva de crítica entre os diversos campos teóricos substantivamente diferentes, o que contradiz uma marca da Etnomatemática d`ambrosiana em relação à Matemática.

Para defendermos a idéia da apropriação apenas parcial da perspectiva lakatosiana, utilizamos, por um lado, o próprio depoimento de D'Ambrosio e, por outro, a idéia de que a crítica histórica, filosófica le ontológica) d'ambrosiana em relação à Matemática, configura-se uma contradição em relação ao relativismo ontológico dos PPC's lakatosianos. Primeiro porque este relativismo preconiza a irrefutabilidade e, portanto, a impossibilidade de crítica ao núcleo firme de tais Programas. Segundo, por que esses Programas, formulados como metodologia geral e normativa e, sobretudo, para o âmbito das ciências empíricas, não se aplicam pacificamente a ciências formais como é o caso da Matemática que d`ambrosio considera uma etnomatemática. 
A este respeito, passemos ao relato de D`Ambrosio na entrevista concedida à Miarka (2011), que pergunta-lhe: "(...) o senhor assume esse programa do mesmo modo como Lakatos, como programa de investigação, possivelmente progressivo, ou tem alguma diferença?", ao que D'Ambrosio responde:

[...] essa angústia de dizer etnomatemática, o que é matemática, ficar preso a isso começou a me incomodar e aí eu vi o Lakatos que também tentou se livrar desse negócio do Kuhn e do Popper e falou isso aí não para. A gente tá mudando sempre, como eu mudei. Comecei pensando, não posso negar que um ponto de partida foi matemática comparada com outras culturas. Bom, aí eu quero me livrar disso. Bom, tô tentando me livrar e provavelmente acabo a minha vida sem conseguir me livrar totalmente disso. Por isso eu chamo um programa, e nesse programa eu me inspirei no Lakatos porque o programa carrega nele esse negócio de dinâmica. Não é uma coisa terminada. Ele não te dá uma teoria final. Foi aí que eu... por isso que eu falei no Lakatos em alguns trabalhos[...].O que me impressionou foi essa dinâmica. Não é uma coisa terminada. É uma coisa em busca. Por isso é um programa de pesquisa. Você não... um programa de pesquisa você tá fazendo a pesquisa, você tá fazendo, você tá evoluindo nessa pesquisa, que é o que eu acho que o Programa Etnomatemática eu vejo assim. Por isso eu passei a usar... abrandar um pouco aquilo que você falou, matemática de uma certa etnia. Não, abranda isso. Isso é Programa Etnomatemática. Essa é a ideia (MIARKA, 2011, p.65-66).

Ressalta neste depoimento de D'Ambrosio, em primeiro lugar, a importância que a natureza do "ponto de partida" tem para a (sua) teoria. Nota-se que a perspectiva lakatosiana não resolve completamente, para ele, a questão do "aprisionamento" teórico relativo à Matemática, quando afirma: "estou tentando me livrar e provavelmente acabo a minha vida sem conseguir me livrar totalmente disso." Ou ainda: "Por isso eu passei a usar... abrandar um pouco aquilo que você falou, matemática de uma certa etnia. Não, abranda isso" (Grifos meus).

Portanto, acreditamos que se explica na adesão, ainda que parcial, da Ełnomatemática d'ambrosiana aos PPC's lakatosianos, e/ou na referida contradição entre eles, a natureza da diferença substantiva que dificulta, na prática, a inteligibilidade ontológica da categoria Trabalho como princípio 
educativo, ou onto-criativo, em sintonia com a Etnomatemática, na crítica que D'Ambrosio constituiu como base da sua concepção.

Neste sentido, entendemos que tal dificuldade fragiliza esta crítica, sobretudo para entendermos e enfrentarmos os problemas educacionais atuais.

Acreditamos que se justifica o fato de D'Ambrosio não ter resolvido completamente (ou ontologicamente) o seu ponto de partida original, através do investimento na "dinâmica" da perspectiva lakatosiana. Justificase, por um lado, porque a mencionada "dinâmica" refere-se apenas a teorias auxiliares e observacionais que "orbitam" o cinturão protetor, além disso, vinculadas a um núcleo duro (convencionalmente irrefutável) que, deste modo, caracteriza o relativismo e a ontologia lakatosiana. Por outro lado, o relativismo epistemológico e histórico da Etnomatemática d'ambrosiana, diferentemente da metodologia normativa dos PPC's de Lakatos, é coerente com o fundamento ontológico de sua crítica à Matemática, no interior da história e da filosofia da ciência. Portanto, embora D’Ambrosio se inspire no relativismo lakatosiano, não o concebe, como este, normativamente, mas o constitui histórica e criticamente em sua perspectiva ontológica.

\section{CONSIDERAÇÕES FINAIS}

Temos plena consciência das dificuldades teóricas, epistemológicas e políticas em abordar a relação a que nos propomos, a partir de idéias marxistas, aparentemente mais rígidas do que as idéias d'ambrosianas, aparentemente mais abertas (livres). Entretanto, entendemos que no sentido radical e decisivo do plano ontológico, as concepções d'ambrosianas não apenas convergem, mas se fortalecem quando relacionadas à perspectiva da dialética materialista e histórica presente na categoria trabalho.

Neste sentido, entendemos que 0 enraizamento da atividade pensante na materialidade do ser, como fundamento ontológico em Marx, 
aproxima-se da concepção d'ambrosiana de "consciência", concebida como síntese dialética entre "conhecimento" e "comportamento".

Com base em tais pressupostos, consideramos que a crítica d'ambrosiana não apenas à Matemática, mas também à ciência hegemônica atual, constitui-se não em qualquer crítica, mas em crítica teórica e epistemológica radicada em um plano ontológico, diferente do de Lakatos. Neste sentido, a crítica, não apenas possível, mas como princípio, necessária, em D`Ambrósio, se aproxima de uma espécie de heurística que, segundo Duayer (2010), constitui a organização geral da obra de Marx.

Em primeiro lugar, a crítica teórica tem de mostrar que a teoria criticada, nos termos de sua própria descrição, é fatalmente inconsistente, falsa, superficial etc. Em segundo, tem de prover uma descrição alternativa na qual demonstra a objetividade e a necessidade da teoria criticada. (...) que são formas de pensamento que, embora falsas, imaginárias, superficiais etc., são (...) socialmente válidas, úteis e eficazes. De modo que a crítica desloca-se imediatamente das formas de pensamento para as estruturas sociais que suscitam e necessitam idéias falsas nos sujeitos (DUAYER, 2010, p.79).

Partindo da crítica ontológica ao arcabouço teórico que sustenta o modelo atual de ciência, incluindo-se aí a Matemática, a serviço das estruturas político-econômicas e sociais dominantes comandadas pelo sistema capitalista nacional e internacional, vislumbramos na aproximação Etnomatemática-Trabalho, a possibilidade de criticar e desvelar a objetividade, o enraizamento e a eficácia social das idéias dominantes na sociedade, bem como o caráter histórico e, por isso, transitório, não só dessas idéias, mas das estruturas sociais que as engendram.

É neste sentido que reside, a nosso ver, o potencial teóricopedagógico de reflexão e ação da relação entre a Etnomatemática d'ambrosiana e a categoria trabalho no Materialismo Histórico e Dialético.

\section{REFERÊNCIAS}

BARATA-MOURA, J. Materialismo e Dialética, ou da Ontologia em Marx. 2008. Disponível em: <http://documents.tips/documents/barata-moura- 
materialismo-e-dialectica-ou-da-ontologia-em-marx.html>. Acesso: em 28 Out. 2015.

BARATA-MOURA, J. O Trabalho da Educação. Revista Trabalho Necessário. Niterói, Ano 13, n. 20/2015. Disponível em <www.uff.br/trabalhonecessario>. Acesso: em 10 Jan. 2016.

D'AMBROSIO, U. Etnomatemática: elo entre tradições e a modernidade. $\left(2^{a}\right.$ ed.) Belo Horizonte: Autêntica, 2009.

D'AMBROSIO, U. Educação Matemática da teoria à prática. $4^{a}$ edição. São Paulo: Papirus, 1996.

D’AMBROSIO, U. Educação para uma sociedade em transição. São Paulo: Pairus, 1999.

D'AMBROSIO, U. O que é ser humano? Disponível em <http://evolucaocriadora.blogspot.com.br/2010/05/o-que-e-ser-humanobiratan-dambrosio.html>. Acesso em: 28 Out. 2015.

DUAYER, M. Relativismo, Certeza e Conformismo: Para uma Crítica das Filosofias da Perenidade do Capital. Revista da Sociedade Brasileira de Economia Politica, v. 27, p. 58-83, 2010.

DUAYER, M. Antirrealismo e absolutas crenças relativas. In: MIRANDA, F.M.; MONFARDINI, R.D. (Orgs.). Ontologia e Estética: volume I. - $1^{a}$ edição. Rio de janeiro: Conseqüência, 2015. 172p. - (Coleção NIEP-Marx; v.2).

FERREIRA, E. S. Programa de Pesquisa Científica Etnomatemática. Revista Brasileira de História da Matemática, n. 1, p. 273-280, dez. 2007.

FRIGOTTO, G. O trabalho como princípio educativo no projeto de educação integral de trabalhadores - Excertos, 2005. Disponível em: <http://redeescoladegoverno.fdrh.rs.gov.br/upload/1392215839_O\%20TRABA LHO\%20COMO\%20PRINC\%C3\%8DPIO\%20EDUCATIVO\%20NO\%2OPROJETO.pdf >. Acesso em: 20 Jun. 2014.

FRIGOTTO, G. Contexto e Sentido Ontológico, Epistemológico e Político da Inversão da Relação Educação e Trabalho para Trabalho e educação. Revista Contemporânea de Educação, v. 20, p. 7-25, 2015.

LAKATOS, I. La metodología de los programas de investigación científica. Madrid: Alianza, 1989.

MARAFON, A. C. M. Acerca do programa de pesquisa Etnomatemática. In: Congresso Brasileiro de Etnomátematica, n.1, 2000, São Paulo. Anais do $1^{\circ}$ Congresso... São Paulo: Faculdade de Educação da Universidade de São Paulo. 2000. Disponível em: < http://www2.fe.usp.br/ etnomat/siteantigo/anais/Adriana.html>. Acesso em: 10 Jan. 2016.

MARX, K. Manuscritos econômico-filosóficos e outros textos escolhidos. São Paulo: Abril Cultural. 1978. (Coleção Os Pensadores). 
MIARKA, R. Etnomatemática: do ôntico ao ontológico. Tese (Doutorado em Educação Matemática). Instituto de Geociências e Ciências Exatas, Universidade Estadual Paulista, Rio Claro, 2011.

Recebido em: Março de 2017 Aceito em: Abril de 2017 